\title{
Effects of shRNA targeting maspin on invasion of gastric carcinoma SGC7901 cell line
}

\author{
YAYING YANG ${ }^{1}$, HAIPENG SHI $^{2}, \mathrm{XIUJUN} \mathrm{LI}^{1}$ and YONGFEN YI ${ }^{1}$ \\ ${ }^{1}$ Department of Pathology, Molecular Medicine and Tumor Center, Chongqing Medical University, Yixueyuan Road 1, \\ Chongqing 400016; ${ }^{2}$ Department of Pathology, Chengdu Second People's Hospital, Chengdu 610000, Sichuan, P.R. China
}

Received June 25, 2010; Accepted September 9, 2010

DOI: $10.3892 /$ or_00001069

\begin{abstract}
Maspin is a member of the serpin (serine protease inhibitor) family of protease inhibitors known to have tumor suppressor activity in diverse human cancers. However, maspin gene function and the molecular aspects in gastric carcinoma remain largely unclear. To investigate the effects of maspin on invasion of gastric carcinoma SGC7901 cell line and the underlying molecular mechanism involved in this process, we cloned short hairpin oligoes (shRNA) targeting maspin into plasmid pGenesil-1.1 eukaryotic expression vector and then transfected the recombinant plasmid pGenesil-maspin into gastric carcinoma SGC7901 cells using Lipofectamine 2000. After the maspin expression was successfully knocked down, the number of cells invading through Matrigel was obviously increased $(\mathrm{P}<0.05)$ in the Transwell chamber assay. By detection of reverse transcription polymerase chain reaction (RT-PCR) and Western blot analysis, respectively, we found that mRNA and protein of UPA, VEGF-C were increased significantly, and the protein level of MMP7 was also increased $(\mathrm{P}<0.05)$. These results suggested that maspin gene could inhibit invasion of gastric cancinoma SGC7901 cells and this inhibition maybe result from the interaction between maspin and UPA, MMP7, or VEGF-C.
\end{abstract}

\section{Introduction}

Maspin is a $42 \mathrm{kD}$ tumor suppressor member of the serpin (serine protease inhibitor) family, originally discovered in normal mammary epithelium (1). The protein is encoded by a gene on chromosome 18q21.3 and has been demonstrated in multiple tissues including epithelium of the breast, prostate, epidermis, lung, and in stromal cells of the cornea (2). Depending on cell type, Maspin is found localized to the cytoplasm, nucleus, the membrane of epithelial cells and the extracellular matrix (ECM). Multiple clinical studies have

Correspondence to: Professor Yongfen Yi, Department of Pathology, Molecular Medicine and Tumor Center, Chongqing Medical University, Yixueyuan Road 1, Chongqing 400016, P.R. China

E-mail: yiyongfen1953@yahoo.com.cn

Key words: shRNA, maspin, gastric carcinoma, invasion confirmed that loss of maspin expression was a negative prognostic factor in diverse human cancers (3-8). Reintroduction of maspin into tumor cells inhibits growth, cell migration and invasion, angiogenesis, and increases cell adhesion and the sensitivity to apoptotic stimulation (9-12), all of which are hallmarks of a tumor suppressor.

Despite enhanced methods of detection and treatment, gastric carcinoma remains one of the most aggressive malignancies, with an extremely poor prognosis, and is the second leading cause of cancer death worldwide (13). Most newly diagnosed patients will present with incurable disease, and have a median survival of less than 1 year (14), so it is important to explore carcinogenesis and molecular mechanisms of gastric carcinoma to improve prevention and treatment. However, there are two opposing views on the role of maspin in human gastric carcinoma. One is that maspin is a tumor suppressor because of the loss and reduced expression in gastric carcinoma $(15,16)$; the other is that maspin may be a gastric cancer-causing gene because of the higher expression in gastric carcinoma than that in normal gastric mucosa (17), and there was a significant correlation between the incidence of maspin-positive tumour staining and lymph node metastasis (18). We recently demonstrated that maspin expression was significantly related to the depth of invasion and lymph node metastasis of gastric carcinoma. Furthermore, by immunohistochemical detection, we found that maspin had a negative correlation with MMP7 and UPA in gastric carcinoma.

In the present study, the maspin-specific shRNA expression vector was constructed and transfected into cultured gastric carcinoma cells SGC7901. The efficacy of the vector in interference with maspin was confirmed by RT-PCR and Western blot analysis. By observation of the invasion ability, detection of uPA, VEGF-C and MMP7 mRNA and protein expression, we further studied and discuss the gene function of maspin in gastric carcinoma and the underlying molecular mechanisms.

\section{Materials and methods}

Cell culture. Gastric carcinoma SGC7901 cells were cultured in RPMI-1640 medium (Hyclon, USA) supplemented with $10 \%$ fetal bovine serum (FBS), penicillin (100 units $/ \mathrm{ml})$ and streptomycin $(100 \mu \mathrm{g} / \mathrm{ml})$ at $37^{\circ} \mathrm{C}$ in a humidified, $5 \% \mathrm{CO}_{2}$ atmosphere. 
Table I. Primer sequence of target genes for RT-PCR.

\begin{tabular}{ll}
\hline Genes & Primer sequence \\
\hline GAPDH & 5'-ACGGATTTGGTCGTATTGGG-3' $(\mathrm{bp})$ \\
& 5'-TGATTTTGGAGGGATCTCGC-3' \\
maspin & 5'-CACTGGGCAATGTCCTCTTC-3' \\
& 5'-TGGTCTGGTCGTTCACACTG-3' \\
uPA & 5'-GCT GTG AGA TCA CTG GCT TTG-3' \\
VEGF-C & 5'-CCT TGG AGG GAA CAG ACG AG-3' \\
& 5'-CTT CTT CTC TGT GGC GTG TTG T-3' \\
MMP7 & 5'-GTC TCT TCT GCT CTT GAG TTG AGG-3' \\
& 5'-AGA TGT GGA GTG CCA GAT GT-3' \\
& 5'-TAG ACT GCT ACC ATC CGT CC-3' \\
\hline
\end{tabular}

Construction and transfection of maspin shRNA expression vector. shRNA expression vector pGenesil-1.1 (Genesil Biotechnology, Wuhan, China) which can express enhanced green fluorescent protein (EGFP) was prepared. Oligonucleotides specific for maspin were designed as follows: maspin sense (5'-CAGGGTCCTCTTCTCTCCAATCTTTC AAGACGAGATTGGAGAGAAGAGGACTTTTTTG-3') and maspin antisense (5'-AGCTCAAAAAAGTCCTCTTCT CTCCAATCTCGTCTTGAAAGATTGGAGAGAAGAGG AC-3'). The sequences 5'-GATCCGACTTCATAAGGCGC ATCGTTCAAGACGGCATGCGCCTTATGAAGTCTTTT TTGTCGACA-3' (sense), and 5'-AGCTTGTCGACAAA AAAGACTTCATAAGGCGCATGCCGTCTTGAAGCATG CGCCTTATGAAGTCG-3' (antisense) were used as a scrambled RNAi control. The annealed double stranded oligonucleotides were ligated into the SacI sites of pGenesil1.1 vector and the constructs were verified by DNA sequencing. SGC7901 cells were transfected with the pGenesil-maspin, pGenesil-scramble and pGenesil-1.1 vector using Lipofectamin 2000 (Invitrogen, USA) according to the manufacturer's instructions. After transfection $(12,24$ and $48 \mathrm{~h}$, respectively), EGFP expressions of 5 visual fields (10x20 times) were randomly observed under a fluorescence microscope, and the transfection efficiency was calculated as: green fluorescent cells/total cells x $100 \%$. Stable clones were generated for further experiments by selection in complete culture medium containing $400 \mu \mathrm{g} / \mathrm{ml} \mathrm{G} 418$ (Gibco, USA).

Reverse transcription-polymerase chain reaction (RT-PCR). RT-PCR was performed to access transcripts of maspin, uPA, VEGF-C and MMP7 expressions after transfection. Total RNAs of SGC7901 cells were extracted by TRIzol (Invitrogen) reagent, and according to the manufacturer's protocol of RT reagent kit (Takara, Dalian, China), we synthesized successfully first-strand cDNAs from $1 \mu 1$ of total RNA using $0.5 \mu 1$ oligo (dt) primer, $1 \mu 1 \mathrm{dNTP}$ mixture, $0.5 \mu 1$ AMV Reverse Transcriptase (Promega, Mannheim, Germany), $0.25 \mu 1$ RNase inhibitor, $3.75 \mu 1$ RNase Free $\mathrm{H}_{2} \mathrm{O}$ and $1 \mu \mathrm{l} 10 \mathrm{X}$ RT buffer. Each first-strand cDNA of target genes was amplified under its appropriate parameters.

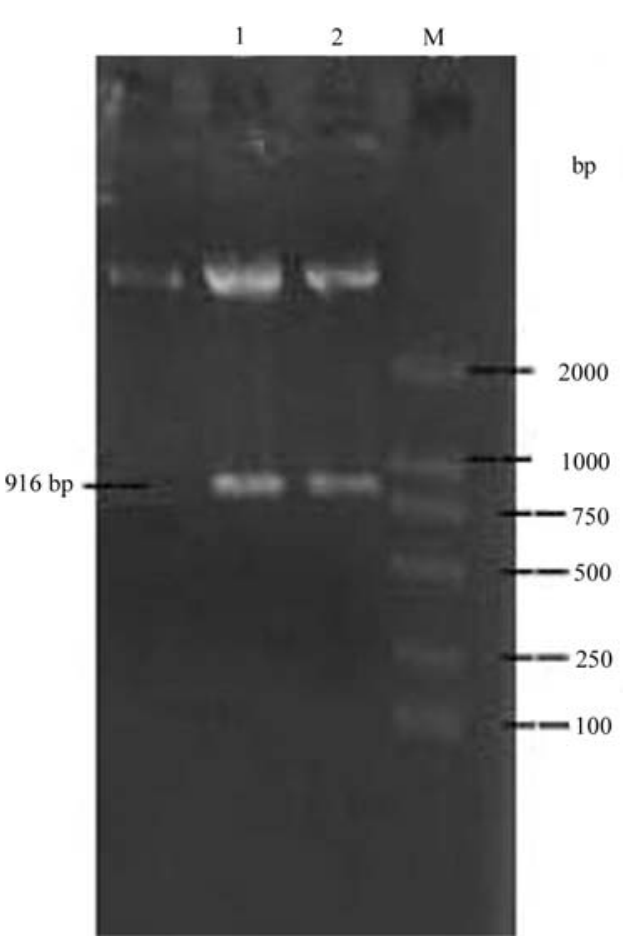

Figure 1. Electrophoresis of the recombinant after restriction endonuclease digestion. M, DL2000 marker; lanes 1 and 2, maspin.

RT-PCR products were analyzed by $2 \%$ agarose gel electrophoresis. Images were captured with Bio-Rad and analyzed with Quantity One Software. The entire experiments were repeated at least three times. Amplification of human glyceraldehyde-3-phosphate dehydrogenase (GAPDH) gene transcripts was performed simultaneously to confirm RNA integrity, efficiency and for quantification of cDNA. All the primers of target genes for RT-PCR are listed in the Table I.

Western blot analysis. Western blot analyses were performed to detect the expression of maspin, uPA, VEGF-C and MMP7 protein after transfection. SGC7901 cells were collected by centrifugation and homogenized in $400 \mu 1$ extraction buffer 

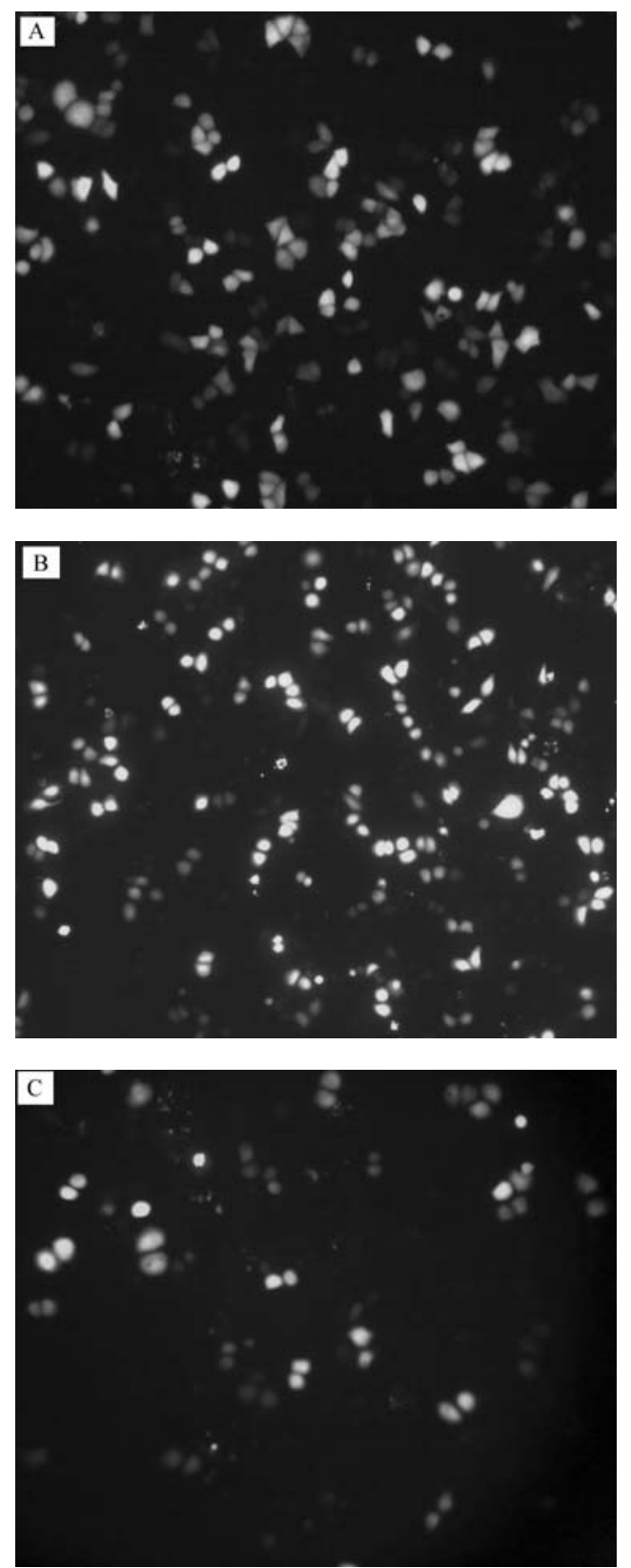

Figure 2. Phase contrast and GFP expression under fluorescence microscope. (A) 12 h; (B) 24 h; (C) 48 h (original magnification, x200).

PRO-PREP ${ }^{\text {Tм }}$ (SBS Genetech Co., Ltd., Beijing, China) at $-20^{\circ} \mathrm{C}$ for $20 \mathrm{~min}$. Equal amounts of proteins (according to Bradford assay) and molecular mass marker were denatured and subjected to a $10 \%$ SDS-polyacrylamide gel electrophoresis. Proteins were electrotransferred to $0.45 \mu \mathrm{m}$ nitrocellulose membranes (Millipore, Bedford, MA, USA) in $25 \mathrm{mM}$ Tris-base, $190 \mathrm{mM}$ glycine, and 20\% methanol using a semi-dry blotter. Non-specific binding was blocked overnight with $20 \%$ non-fat milk and Tris-buffered saline, containing $0.01 \%$ Tween-20. The membranes were incubated with primary antibody at $4^{\circ} \mathrm{C}$ overnight, washed and incubated at room temperature for $1 \mathrm{~h}$ with appropriate horseradish peroxidase-conjugated secondary antibody (Biosythesis Biotechnology Co., Ltd., Beijing, China), then detected by chemiluminescence (ECL; ChemiDoc XRS). Bands corres-

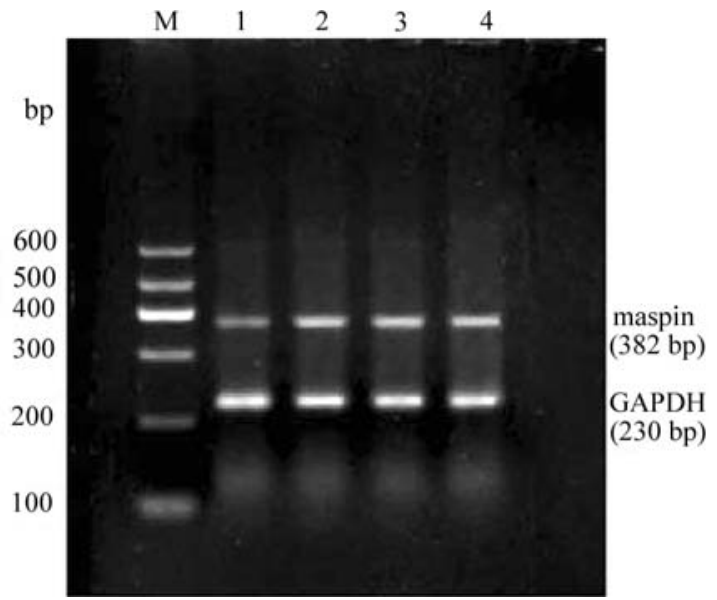

Figure 3. RT-PCR analysis of the maspin mRNA: maspin gene was cloned from the cDNA library with production of 382 bp by PCR. M, DNA marker; lane 1, transfection with pGenesil-maspin; lane 2, lipofectin group; lane 3, transfection with pGenesil-scramble; lane 4, transfection with pGenesil-1.1.

ponding to different proteins were scanned and the respective areas and optic density (OD) were determined by Quantity One 4.5.2. The relative densities were calculated by normalizing the OD of each blot with that of GAPDH. Primary antibodies used: anti-maspin, anti-uPA, anti-VEGF-C, anti-MMP7 and anti-GAPDH (Boster Biological Engineering Co., Ltd., Wuhan, China).

Invasion assays. For Transwell chamber-based invasion assays, equal amounts of cells were loaded into an insert provided with serum-free medium and allowed to pass through an $8-\mu \mathrm{m}$ pore polycarbonate filter, which had been either precoated with $100 \mu \mathrm{g}$ of Matrigel (Becton-Dickinson, San Jose, CA) for invasion assay or left uncoated for motility assay. Medium supplemented with $10 \%$ fetal calf serum was added to the bottom chamber. Cells on the upper surface of filters were wiped out after $24 \mathrm{~h}$, and those on the undersurface were stained with $1 \%$ amino toluene blue and counted under a microscope.

Statistical analyses. All data are expressed as mean \pm SEM. Statistical analysis of the data was performed using Student's t-test. $\mathrm{P}<0.05$ was considered significant.

\section{Results}

Identification of maspin shRNA expression vector. After restriction endonuclease SalI digestion, a small band of DNA (916 bp) was detected by electrophoresis (Fig. 1). DNA sequencing of the constructs (Invitrogen) showed that there were the same sequences as the target fragments.

Transfection efficiency. Forty-eight hours after transfection, $85 \%$ of SGC-7901 cells appeared high expression of EGFP, and it demonstrated that transfection by Lipofectamine 2000 was very effective (Fig. 2).

Effect of maspin shRNA on maspin expression. As shown in Figs. 3 and 4, maspin mRNA and protein was detected in the 


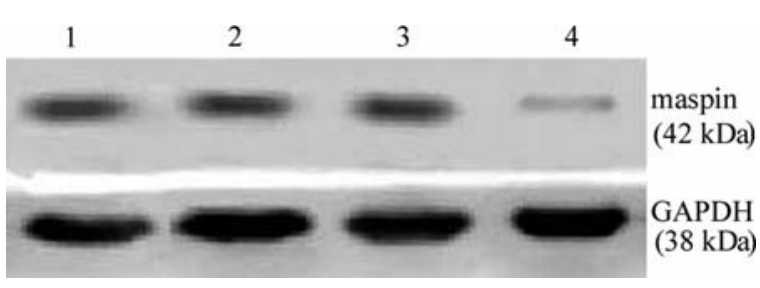

Figure 4. Western blot analysis of maspin protein expression level. Lane 1, Lipofectin group; lane 2, transfection with pGenesil-scramble; lane 3, transfection with pGenesil-1.1; lane 4, transfection with pGenesil-maspin.

Table II. Statistical analysis of maspin mRNA expression $(n=3)$.

\begin{tabular}{llllll}
\hline Group & OD $(\overline{\mathrm{x}} \pm \mathrm{s})$ & & \multicolumn{3}{c}{ P-value } \\
\hline Lipofectin & $0.752 \pm 0.128$ & & & \\
pGenesil-scramble & $0.745 \pm 0.123$ & $>0.05^{\mathrm{a}}$ & & \\
pGenesil-1.1 & $0.738 \pm 0.116$ & $>0.05^{\mathrm{a}}$ & $>0.05^{\mathrm{b}}$ & \\
pGenesil-maspin & $0.168 \pm 0.090$ & $<0.05^{\mathrm{a}}$ & $<0.05^{\mathrm{b}}$ & $<0.05^{\mathrm{c}}$ \\
\hline
\end{tabular}

${ }^{\text {ap }}$ vs. Lipofectin; ${ }^{b} \mathrm{P}$ vs. pGenesil-scramble; ${ }^{\mathrm{c} P}$ vs. pGenesil-1.1.

Table III. Statistical analysis of maspin protein expression $(n=3)$.

\begin{tabular}{llllll}
\hline Group & OD $(\overline{\mathrm{x}} \pm \mathrm{s})$ & & P-value & \\
\hline Lipofectin & $0.54 \pm 0.10$ & & & \\
pGenesil-scramble & $0.58 \pm 0.15$ & $>0.05^{\mathrm{a}}$ & & \\
pGenesil-1.1 & $0.57 \pm 0.13$ & $>0.05^{\mathrm{a}}$ & $>0.05^{\mathrm{b}}$ & \\
pGenesil-maspin & $0.22 \pm 0.08$ & $<0.05^{\mathrm{a}}$ & $<0.05^{\mathrm{b}}$ & $<0.05^{\mathrm{c}}$ \\
\hline
\end{tabular}

${ }^{\mathrm{a} P}$ vs. Lipofectin; ${ }^{\mathrm{b}} \mathrm{P}$ vs. pGenesil-scramble; ${ }^{\mathrm{c}} \mathrm{P}$ vs. pGenesil-1.1.

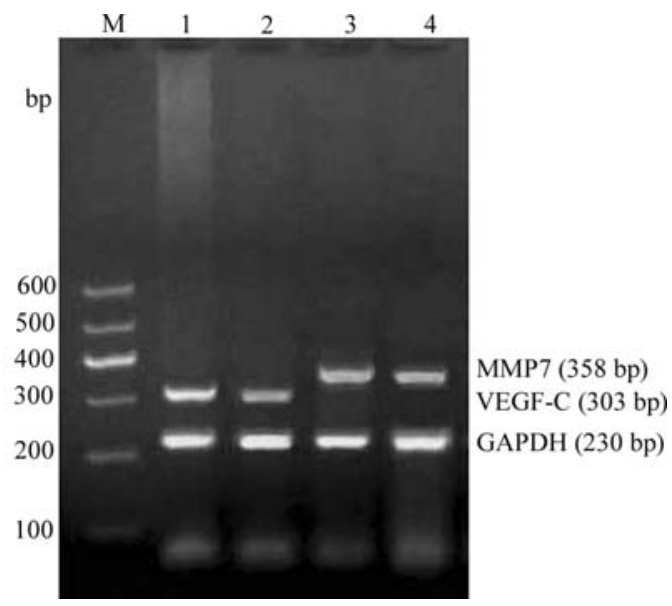

Figure 5. RT-PCR analysis of the VEGF-C, MMP7 mRNA expression. M, DNA marker; lane 1, VEGF-C expression in transfection with pGenesilmaspin; lane 2, VEGF-C expression in transfection with pGenesil-1.1; lane 3, MMP7 expression in transfection with pGenesil-maspin; lane 4, MMP7 expression in transfection with pGenesil-1.1.

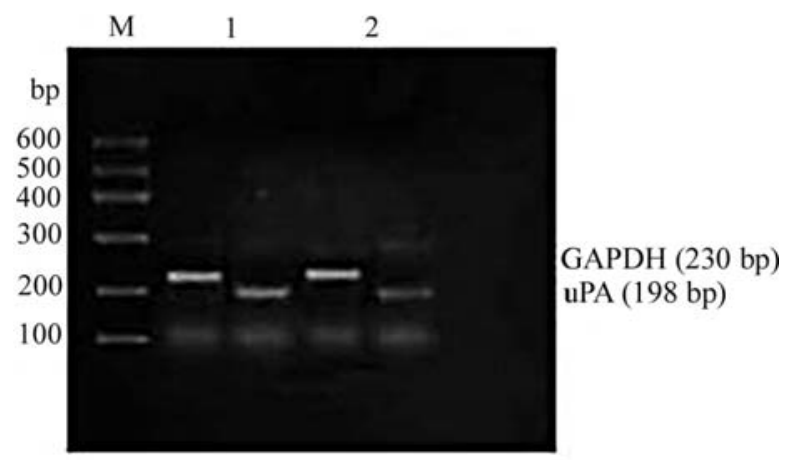

Figure 6. RT-PCR analysis of the uPA mRNA expression. M, DNA marker; lane 1 , transfection with pGenesil-maspin; lane 2, uPA expression in transfection with pGenesil-1.1.

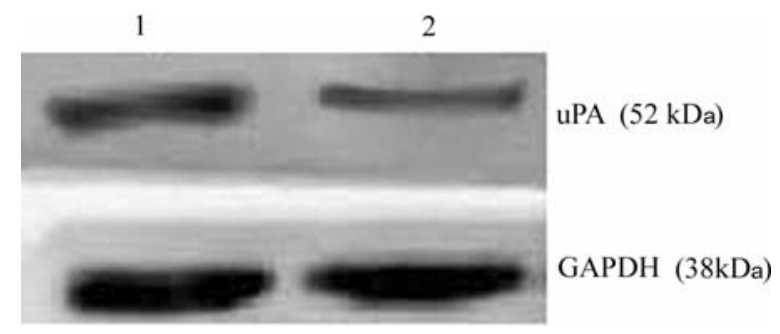

Figure 7. Western blot analysis of uPA protein expression. Lane 1, transfection with pGenesil-maspin; lane 2, transfection with pGenesil-1.1.

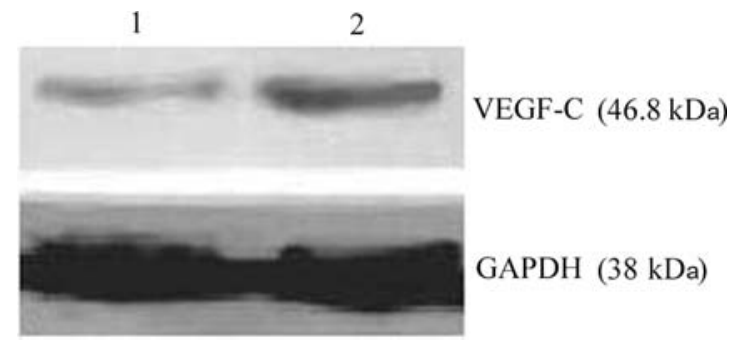

Figure 8. Western blot analysis of VEGF-C protein expression. Lane 1, transfection with pGenesil-1.1; lane 2, transfection with pGenesil-maspin.

SGC7901 cells. There was no difference among stable transfection of pGenesil-scramble, pGenesil-1.1 vector and Lipofectin $(\mathrm{P}>0.05)$. However, maspin was significantly decreased in the stable maspin shRNA-transfected cells $(\mathrm{P}<0.01)$. All of the data (OD) are shown in Tables II and III. These results indicated that the maspin shRNA expression vector used in this study was efficient in knockdown of the expression of maspin in gastric cancer cells SGC7901.

Effect of maspin shRNA on uPA, VEGF-C and MMP7 expression. Compare with transfection of pGenesil-1 vector, stable transfection of pGenesil-maspin showed higher expression of uPA and VEGF-C mRNA $(\mathrm{P}<0.05)$, but there was no difference in MMP7 mRNA expression between them $(\mathrm{P}>0.05)$. In addition, uPA, VEGF-C and MMP7 protein expression of pGenesil-maspin transfection were higher than those of pGenesil-1 vector transfection, and the difference 


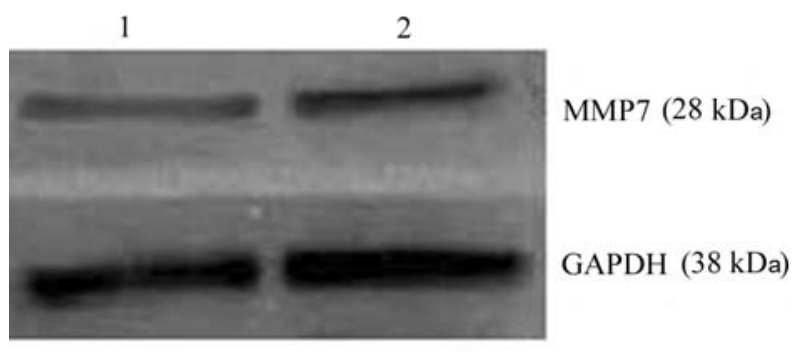

Figure 9. Western blot analysis of MMP7 protein expression. Lane 1, transfection with pGenesil-1.1; lane 2, transfection with pGenesil-maspin.

was significant $(\mathrm{P}<0.05)$ (Figs. 5-9). The data $(\mathrm{OD})$ are shown in Tables IV and V.

Effect of maspin shRNA on cell invasion. In the invasion assay, the average number of migrated cells per field of pGenesil-maspin transfection was $86.8 \pm 2.36$, which was much higher than that of the pGenesil-1 vector transfection

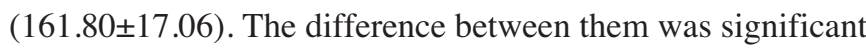
$(\mathrm{P}<0.05)$ (Fig. 10).

\section{Discussion}

RNA interfering (RNAi) is the process by which doublestranded RNA induces potent and specific inhibition of eukaryotic gene expression through the degradation of complementary messenger RNA, and is functionally similar to the processes of post-transcriptional gene silencing $(19,20)$. In recent years, RNAi has been widely applied by researchers to the study of gene function and gene therapy in oncology because of its high specificity and apparent non-toxicity (21). Small hairpin RNA (shRNA) expression vector systems have been established to induce RNA interference (RNAi) in mammalian cells (22), and it was proved to provide longlasting silencing and maximal inhibition of gene expression at low concentration (23). In the present study, a maspin shRNA expression vector was constructed and transfected into SGC7901 cells successfully, and the obvious inhibition of maspin expression was comfirmed by RT-PCR and Western blot detection.
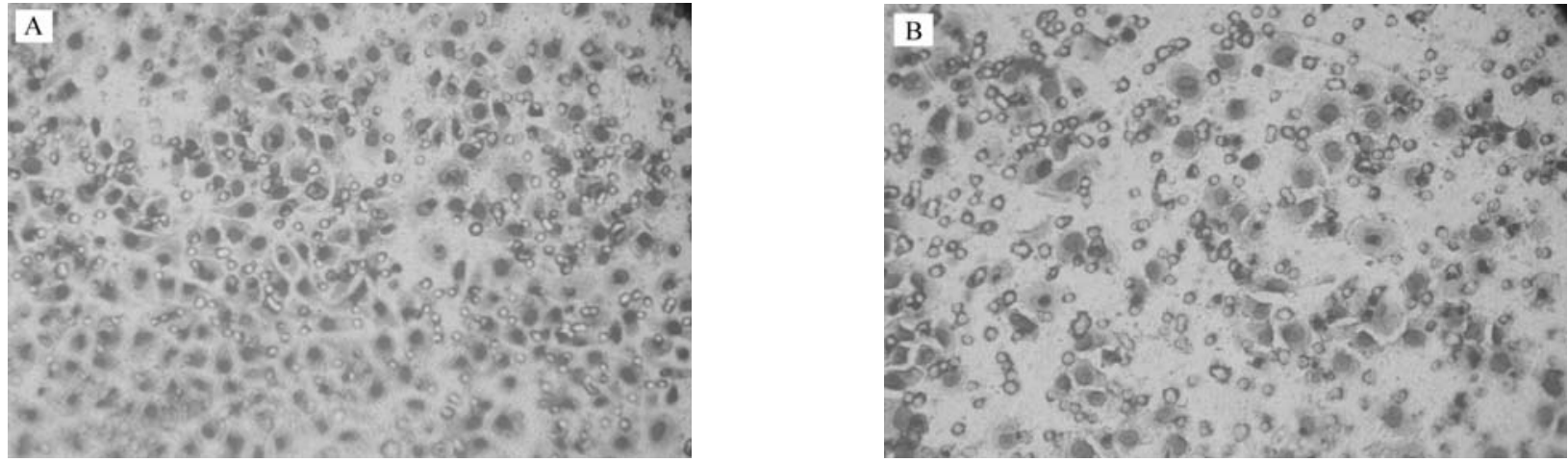

Figure 10. Invasion assays of gastric cancer SGC7901 (original magnification, x200). (A) Transfection with pGenesil-maspin; (B) transfection with pGenesil-1.1 .

Table IV. Statistical analysis of uPA, VEGF-C, MMP7 mRNA expression $(n=3)$.

\begin{tabular}{lccr}
\hline Group & uPA & VEGF-C & MMP7 \\
\hline pGenesil-1.1 & $0.322 \pm 0.134$ & $0.427 \pm 0.164$ & $0.458 \pm 0.137$ \\
pGenesil-maspin & $0.576 \pm 0.067^{\mathrm{a}}$ & $0.726 \pm 0.126^{\mathrm{b}}$ & $0.437 \pm 0.163^{\mathrm{c}}$ \\
\hline
\end{tabular}

${ }^{\mathrm{a}} \mathrm{P}<0.05$ vs. pGenesil-1.1; ${ }^{\mathrm{b}} \mathrm{P}<0.05$ vs. pGenesil-1.1; ${ }^{\mathrm{c}} \mathrm{P}<0.05$ vs. pGenesil-1.1.

Table V. Statistical analysis of uPA, VEGF-C, MMP7 protein expression $(n=3)$.

\begin{tabular}{lccr}
\hline Group & uPA & VEGF-C & MMP7 \\
\hline pGenesil-1.1 & $0.364 \pm 0.107$ & $0.162 \pm 0.079$ & $0.211 \pm 0.071$ \\
pGenesil-maspin & $0.872 \pm 0.156^{\mathrm{a}}$ & $0.475 \pm 0.171^{\mathrm{b}}$ & $0.557 \pm 0.124^{\mathrm{c}}$ \\
\hline
\end{tabular}

${ }^{\mathrm{a}} \mathrm{P}<0.05$ vs. pGenesil-1.1; ${ }^{\mathrm{b}} \mathrm{P}<0.05 \mathrm{vs}$. pGenesil-1.1; ${ }^{\mathrm{c}} \mathrm{P}<0.05$ vs. pGenesil-1.1. 
Serpins comprise a large protein family with diverse biological functions. As a member of the serpin family, maspin has been grouped with the ov-serpin subfamily (Clade B), as maspin exhibits significant sequence similarity to chicken ovalbumin (31\%) (1). There are currently 13 known human ov-serpins, all of them are known functional protease inhibitor (24). Protease inhibition occurs via the serpin reactive site loop (RSL), which is the primary functional domain of the serpin family and has proven necessary for some of maspin's tumor suppressive functions, including adhesion to the cellular matrix and maspin interactions at the cell surface. In an early study of maspin gene in breast carcinoma, Ngamkitidechakul et al (25) found that the RSL peptide alone (amino acids 330-345) is sufficient to induce adhesion of breast cancer MDA-MB-231 cells to fibronectin and that substitution of the ovalbumin RSL with the maspin RSL converted ovalbumin into an active protein able to stimulate adhesion of breast cancer cells to fibronectin.

The relationship between maspin and gastric carcinoma is controversial. Our study showed that maspin gene may be involved in the invasion of gastric carcinoma SGC7901. In invasive assays, the average number of SGC7901 cells which could pass through a filter pre-coated with Matrigel was increased after maspin silencing by RNAi, and as ECM alternatives, Matrigel contains IV collagen, laminin and other components of basement membrane. Crystal structure analysis of maspin has uncovered that the maspin G-helix was shown to adopt both a 'closed' and 'open' configuration. This conformational modification is unique to maspin and results in a reorganization of charged residues to expose a large negatively charged domain centered on the G-helix. The authors hypothesize that this domain might function in ligand binding other domains include a negatively charged region near the D-helix that could represent a possible collagen binding-domain (26).

We found that uPA mRNA and protein in SGC7901 cells were significantly increased after interference of maspin expression. Although maspin does not directly inhibit the activity of urokinase plasminogen activator (uPA), maspin was shown to reduce cell surface-associated urokinase plasminogen activator/urokinase plasminogen activator receptor (uPA/uPAR) by inducing its internalization $(27,28)$. uPA/UPAR complex contributes to transformation from plasminogen to plasmin which can initiate a protease cascade that results in localized degradation of the ECM (such as fibronectin, fibrin and laminin) for the purpose of cell migration (29). Amir et al (30) reported that transfection of maspin gene in the highly invasive MDA-MB-231 breast cancer cells can inhibit hypoxia-induced invasion of metastatic cancer cells by blocking the expression of uPA/uPAR complex. In a more recent research (28), it was demonstrated that pro-uPA zymogen can not be activated just because of its combination with maspin.

High amounts of cytokines secreted by tumor cells can induce the new blood vessels and lymphatic vessels formation which are involved in invasion and metastasis of tumor. In an earlier study of the relationship between maspin and vascular endothelial growth factor (VEGF), which act as important chemoattractants during angiogenesis, it was demonstrated that maspin can act directly on the cultured endothelial cells and prevent mitosis $(31,32)$. However, some researchers found that maspin and VEGF showed no correlation in gastric carcinoma (33). VEGF-C, a member of VEGF family, is the first identified lymph-angiogenic growth factor, and by combination with VEGF-3, it can induce the proliferation and expansion of lymphatic vessels and the following lymphatic invasion and lymph node metastasis (34-36). Our study showed that VEGF-C mRNA and protein expression were increased with the decrease of maspin expression, at the same time the invasive ability of gastric carcinoma cells was enhanced. It suggested that mediated by VEGF-C, maspin can inhibit the invasion and metastasis of gastric carcinoma.

Matrix metalloproteinases (MMPs), a specialized group of enzymes capable of proteolytically degrading extracellular matrix proteins, have been postulated to play an important role in metastasis. MMP7, a member of MMPs, is expressed by tumor cells of epithelial and mesenchymal origin in esophagus, stomach, colorectum, liver, pancreas, lung, skin, breast, and endometrium, it may be used as a biological marker of an aggressive phenotype (37-42). Few studies demonstrated the relationship of maspin and MMP7. In this study, we found that MMP7 protein expression in recombinant plasmid transfection group was significantly increased, whereas there was no significant change in its mRNA expression. MMPs act both upstream and downstream of VEGF (43). An ovarian carcinoma study implied that VEGF could increase MMP7 secretion significantly and enhanced the activity of MMP7, while had no effect on the expression of its mRNA (44). In gastric carcinoma, maspin may also down-regulate MMP7 by inhibiting the expression of VEGF. Moreover, as pro-MMP was activated by uPA/uPAR complex (45), it can be speculated that maspin could down-regulate MMPs by inhibition of uPA.

Overall, maspin gene expression in human gastric cancer SGC7901 cells was inhibited by RNAi technology and the invasive ability of tumor cells was enhanced. It is suggested that maspin gene could inhibit invasion of gastric carcinoma SGC7901 cells and this inhibition maybe result from the interaction between maspin and UPA, MMP7, or VEGF-C.

\section{Achnowledgements}

This study was supported by a grant from the project of Chongqing Educational Committee (No. 040310).

\section{References}

1. Zou Z, Anisowicz A, Hendrix MJ, et al: Maspin, a serpin with tumor-suppressing activity in human mammary epithelial cells. Science 263: 526-529, 1994.

2. Bailey CM, Khalkhali-Ellis Z, Seftor EA and Hendrix MJ: Biological functions of maspin. J Cell Physiol 209: 617-624, 2006.

3. Lee MJ, Suh CH and Li ZH: Clinicopathological significance of maspin expression in breast cancer. J Korean Med Sci 21: 309-314, 2006.

4. Hall DC, Johnson-Pais TL, Grubbs B, Bernal R, Leach RJ and Padalecki SS: Maspin reduces prostate cancer metastasis to bone. Urol Oncol 26: 652-658, 2008.

5. Yoshizawa K, Nozaki S, Okamune A, et al: Loss of maspin is a negative prognostic factor for invasion and metastasis in oral squamous cell carcinoma. J Oral Pathol Med 38: 535-539, 2009. 
6. Chua R, Setzer S, Govindarajan B, Sexton D, Cohen C and Arbiser JL: Maspin expression, angiogenesis, prognostic parameters, and outcome in malignant melanoma. J Am Acad Dermatol 60: 758-766, 2009.

7. Takanami I, Abiko T and Koizumi S: Expression of maspin in non-small cell lung cancer: correlation with clinical features. Clin Lung Cancer 9: 361-366, 2008.

8. Li HW, Leung SW, Chan CS, Yu MM and Wong YF: Expression of maspin in endometrioid adenocarcinoma of endometrium. Oncol Rep 17: 393-398, 2007.

9. Shi HY, Zhang W, Liang R, Abraham S, Kittrell FS, Medina D and Zhang M: Blocking tumor growth, invasion, and metastasis by maspin in a syngeneic breast cancer model. Cancer Res 61: 6945-6951, 2001.

10. Zhang W, Shi HY and Zhang M: Maspin overexpression modulates tumor cell apoptosis through the regulation of Bcl-2 family proteins. BMC Cancer 5: 50, 2005.

11. McKenzie S, Sakamoto S and Kyprianou N: Maspin modulates prostate cancer cell apoptotic and angiogenic response to hypoxia via targeting AKT. Oncogene 27: 7171-7179, 2008

12. Cella N, Contreras A, Latha K, Rosen JM and Zhang M: Maspin is physically associated with [beta]1 integrin regulating cell adhesion in mammary epithelial cells. FASEB J 20: 1510-1512, 2006.

13. Parkin DM, Bray F, Ferlay J and Pisani P: Global cancer statistics, 2002. CA Cancer J Clin 55: 74-108, 2005.

14. Shah MA and Kelsen DP: Gastric cancer: a primer on the epidemiology and biology of the disease and an overview of the medical management of advanced disease. J Natl Compr Canc Netw 8: 437-447, 2010

15. Ito R, Nakayama H, Yoshida K, Oda N and Yasui W: Loss of maspin expression is associated with development and progression of gastric carcinoma with p53 abnormality. Oncol Rep 12: 985-990, 2004.

16. Wang MC, Yang YM, Li XH, Dong F and Li Y: Maspin expression and its clinicopathological significance in tumorigenesis and progression of gastric cancer. World J Gastroenterol 10: 634-637, 2004

17. Song SY, Son HJ, Kim MH, Nam ES, Rhee JC and Park C: Prognostic significance of maspin expression in human gastric adenocarcinoma. Hepatogastroenterology 54: 973-976, 2007.

18. Terashima M, Maesawa C, Oyama K, et al: Gene expression profiles in human gastric cancer: expression of maspin correlates with lymph node metastasis. Br J Cancer 92: 1130-1136, 2005.

19. Hannon GJ: RNA interference. Nature 418: 244-251, 2002.

20. Lee SH and Sinko PJ: siRNA - getting the message out. Eur J Pharm Sci 27: 401-410, 2006.

21. Gartel AL and Kandel ES: RNA interference in cancer. Biomol Eng 23: 17-34, 2006.

22. Brummelkamp TR, Bernards R and Agami R: A system for stable expression of short interfering RNAs in mammalian cells. Science 296: 550-553, 2002.

23. Kim DH, Behlke MA, Rose SD, Chang MS, Choi S and Rossi JJ: Synthetic dsRNA Dicer substrates enhance RNAi potency and efficacy. Nat Biotechnol 23: 222-226, 2005.

24. Silverman GA, Bird PI, Carrell RW, et al: The serpins are an expanding superfamily of structurally similar but functionally diverse proteins. Evolution, mechanism of inhibition, novel functions, and a revised nomenclature. J Biol Chem 276 33293-33296, 2001

25. Ngamkitidechakul C, Warejcka DJ, Burke JM, O'Brien WJ and Twining SS: Sufficiency of the reactive site loop of maspin for induction of cell-matrix adhesion and inhibition of cell invasion. Conversion of ovalbumin to a maspin-like molecule. J Biol Chem 278: 31796-31806, 2003

26. Law RH, Irving JA, Buckle AM, et al: The high resolution crystal structure of the human tumor suppressor maspin reveals a novel conformational switch in the G-helix. J Biol Chem 280: 22356-22364, 2005

27. Biliran $\mathrm{H} \mathrm{Jr}$ and Sheng S: Pleiotrophic inhibition of pericellular urokinase-type plasminogen activator system by endogenous tumor suppressive maspin. Cancer Res 61: 8676-8682, 2001.
28. Yin S, Lockett J, Meng Y, et al: Maspin retards cell detachment via a novel interaction with the urokinase-type plasminogen activator/urokinase-type plasminogen activator receptor system. Cancer Res 66: 4173-4181, 2006.

29. Jo M, Thomas KS, Wu L and Gonias SL: Soluble urokinasetype plasminogen activator receptor inhibits cancer cell growth and invasion by direct urokinase-independent effects on cell signaling. J Biol Chem 278: 46692-46698, 2003.

30. Amir S, Margaryan NV, Odero-Marah V, Khalkhali-Ellis Z and Hendrix MJ: Maspin regulates hypoxia-mediated stimulation of uPA/uPAR complex in invasive breast cancer cells. Cancer Biol Ther 4: 400-406, 2005.

31. Zhang M, Volpert O, Shi YH, et al: Maspin is an angiogenesis inhibitor. Nat Med 6: 196-199, 2000.

32. Nickoloff BJ, Lingen MW, Chang BD, et al: Tumor suppressor maspin is up-regulated during keratinocyte senescence, exerting a paracrine antiangiogenic activity. Cancer Res 64: 2956-2961, 2004.

33. Li JJ, Chen Y, Zhang SM, Wu DY, Wang YP and Xin Y: Pathobiological significance of vascular endothelial growth factor and Maspin expressions in human gastric carcinoma. World J Gastroenterol 10: 2624-2627, 2004.

34. Giatromanolaki A, Koukourakis MI, Stathopoulos GP, et al: Angiogenic interactions of vascular endothelial growth factor, of thymidine phosphorylase, and of p53 protein expression in locally advanced gastric cancer. Oncol Res 12: 33-41, 2000.

35. Yonemura Y, Endo Y, Fujita H, et al: Role of vascular endothelial growth factor $\mathrm{C}$ expression in the development of lymph node metastasis in gastric cancer. Clin Cancer Res 5: 1823-1829, 1999.

36. Ishikawa M, Kitayama J, Kazama S, et al: Expresson of vascular endothelial growth factor C and D (VEGF-C and D) is an important risk factor for lymphatic metastasis in undifferentiated early gastric carcinoma. Jpn J Clin Oncol 33: 21-27, 2003.

37. Aihara R, Mochiki E, Nakabayashi T, Akazawa K, Asao T and Kuwano H: Clinical significance of mucin phenotype, betacatenin and matrix metalloproteinase 7 in early undifferentiated gastric carcinoma. Br J Surg 92: 454-462, 2005.

38. Adachi $\mathrm{Y}$, Itoh F, Yamamoto H, Iku S, Matsuno K, Arimura Y and Imai K: Retinoic acids reduce matrilysin (matrix metalloproteinase 7) and inhibit tumor cell invasion in human colon cancer. Tumour Biol 22: 247-253, 2001.

39. Yamamoto H, Iku S, Adachi Y, Imsumran A, et al: Association of trypsin expression with tumour progression and matrilysin expression in human colorectal cancer. J Pathol 199: 176-184, 2003.

40. Yamamoto H, Horiuchi S, Adachi Y, Taniguchi H, Nosho K, Min Y and Imai K: Expression of ets-related transcriptional factor $\mathrm{E} 1 \mathrm{AF}$ is associated with tumor progression and overexpression of matrilysin in human gastric cancer. Carcinogenesis 25: 325-332, 2004.

41. Jones LE, Humphreys MJ, Campbell F, Neoptolemos JP and Boyd MT: Comprehensive analysis of matrix metalloproteinase and tissue inhibitor expression in pancreatic cancer: increased expression of matrix metalloproteinase-7 predicts poor survival. Clin Cancer Res 10: 2832-2845, 2004.

42. Okayama H, Kumamoto K, Saitou K, et al: CD44v6, MMP-7 and nuclear $\mathrm{Cdx} 2$ are significant biomarkers for prediction of lymph node metastasis in primary gastric cancer. Oncol Rep 22: 745-755, 2009

43. Cebrahem Q, Chaurasia SS, Vasanji A, et al: Cross-talk between vascular endothelial growth factor and matrix metalloproteinases in the induction of neovascularization in vivo. Am J Pathol 176: 496-503, 2010.

44. Wang FQ, So J, Reierstad S, et al: Matrilysin (MMP-7) promotes invasion of ovarian cancer cells by activation of progelatinase. Int J Cancer 114: 19-31, 2005.

45. Murphy G, Stanton H, Cowell S, et al: Mechanisms for pro matrix metalloproteinase activation. APMIS 107: 38-44, 1999. 